\title{
Supply chain SWOT analysis of Chinese circulation enterprises from supply side angle
}

\author{
Pingping Zhang, Lianhui Hui \\ Wuyi University, Canghou Street, Jiangmen, China \\ 2515876670@qq.com,hnxtllh@163.com
}

\begin{abstract}
Keywords: supply-side structural reform, new economy and new normal, circulation enterprises, supply chain, SWOT
\end{abstract}

\begin{abstract}
: supply-side structural reform is a major innovation to guide economic development, and also an inevitable requirement to adapt to the new normal economy. Circulation enterprises connect upstream and downstream and plays an important role in supply-side structural reform. On the premise of the reform, strengths, weaknesses, opportunities and challenges faced by supply chain system through SWOT analysis and the countermeasures are provided.
\end{abstract}

\section{Introduction}

On November 10, 2015, President Xi Jinping put forward the supply-side structural reform for the first time, and stressed the need to strengthen the supply-side structural reform while expanding the total demands. On the Chinese Economy 50 Forum on February 19, 2016, he took the deepening the supply-side structural reform and improving development quality in an all-round way. The supply-side structural reform is a major turning point in China's macroeconomic regulation and control, but also a fundamental change in the mode of economic growth, which requires all enterprises on the links of production and circulation to fulfill their own obligations and cooperate (Gang Gong, 2016). However, Chinese circulation enterprises are developed in an extensive manner, the urban and rural development is not balanced, the network layout structure is unreasonable, the degree of internationalization, informatization and standardization is low, and problems of high costs and low efficiency continue to highlight. Similarly, logistics is facing a new situation and challenges: The industry growth continued to slow, freight prices are low, social logistic cost is high and hard to decline, and the profit spaces of enterprises are squeezed. Various contradictions increase the difficulty of market regulation and industry management(Liming He, 2016).Promoting supply-side structural reform of circulation enterprises may be realized by optimizing the division and collaboration among circulation enterprises, consumers and producers, establishing global supply chain system, occupy the domestic and foreign market with high quality and effective supply, effectively curb the poor supply while reducing the cost of commodity circulation and realizing the transformation and upgrading goals of circulation enterprises. In the supply-side structural reform, the circulation enterprises are facing opportunities. Due to the conditions of Chinese technological resources, circulation enterprises are faced with challenges and threats in the supply chain biosphere. This paper takes the SWOT as the analysis template, briefly analyzes the advantages, weaknesses, 
opportunities and challenges of circulation enterprises on supply chain and puts forward some corresponding countermeasures.

\section{Supply-side structural reform and economic new normal}

\subsection{Supply-side structural reform}

\subsubsection{Definition of supply-side structural reform}

It refers to that promoting economic development is achieved through liberating productive force and enhancing competitiveness starting from sides of supply and production. Specifically, it is required to clean up zombie enterprises, eliminate backward production capacity and locate the development direction in the emerging fields, innovation fields, and creating new economic growth point(Zhi Li, Jinfeng Yuan, 2016). The original meaning of supply-side structural reform is to strengthen supply-side structural reform and focus on improving supply system quality and efficiency while expanding moderately the total demands. The core is to improve the total factor productivity. This paper mainly studies the environment of supply chain under the reform.

\subsubsection{Changes brought by supply-side structural reform}

(1) Supply chain logistics service demand side has undergone major changes in the environment of Internet plus. For example Belt and Road Initiative brought unlimited business opportunities for logistics enterprises; adjustment of economic development structure and high-end manufacturing focus on the optimization of supply chain; distribution business supply chain is accelerated rapidly, business logistics demands emerge, and demands of environmental protection and green logistics grows(Xinyan Wu2015,).

(2) Supply side constantly adapts to changes in demand to deepen the reform, which is reflected in group logistics enterprises focus on strategic adjustment and transformation and upgrading; traditional logistics enterprises are upgraded, and the integration service of warehousing and distribution is evident increasingly; the third party logistics enterprises accelerate the implementation of supply chain integration services(Hua Zhu, 2017); professional logistics develops fast; mergers and acquisitions and the market concentration gradually improve; logistics enterprise information technology is upgraded widely; green logistics has become a new norm in enterprises.

(3) The operating environment of Logistics enterprises continue to improve, which is reflected in that government issues policies to support the development of the logistics industry; builds the integrity logistics system to continuously develop(Hua Zhu, 2017), the new third board continues to heat up and become a new way to securitize the capital of logistics enterprises, and logistics infrastructure construction has made great progress.

\subsection{Economic new normal}

Concept of new normal in different contexts differs. Put the new normal of Chinese economy in the market economic context, it does not refer to the statement of economic development, but the transition of Chinese economic situation. It cannot go back the old normal of planned economy before the reform and opening up, and needs to change from that economic development was in the industrialization primary stage 30 years later after the reform and opening up, the government promoted the economic-extensive periodic high-speed fluctuated growth, benefit distribution structure and industrial structure were distorted, the development situation between people to nature was not harmonious to that operation mechanism more rely on the market's own rules, economic 
growth, economic structure and industrialization enter the middle and later period when these are in line with objective requirement, benefit allocation is more fair and rational and people and nature develop in a harmonious manner. The core is to form new market economic rule, operation mechanism and the new market structure and mode.

\section{Supply-side structural reform changes the environment of circulation enterprises.}

Supply-side structural reform is of great significance to the change of the development environment of China's circulation enterprises, which is embodied in the following two aspects:

On the one hand, the reform promotes the circulation enterprises to adapt to the requirements of the new era, eliminate excess capacity, speed up their own transformation and upgrading, and further promote the integration of virtual and physical markets.

Chinese circulation industry is the short board and the bottleneck of supply side, China's circulation enterprises develop extensively, network layout is not perfect, internationalization, standardization and informationization level is low, circulation cost is high, supply and demand information is inconsistent, efficiency is low and other problems are evident, which lead to the dilemmas of imbalance of production structure and high volume of inventory for circulation enterprises, which hinders the development of circulation enterprises(2017, Chaofang,Yuan). In the background of the reform, the government reduces the intervention to the competitive industry, especially the administrative intervention in the process of diminishing the industrial capacities, and provide a favorable policy environment for all kinds of circulation enterprises to remove excess capacity. Circulation enterprises can cultivate a number of downstream new industries, and bring the industrial transformation and upgrading of upstream overcapacity through downstream enterprises indirectly.

On the other hand, the reform can promote circulation enterprises to carry on technological innovation, improve the enterprises' circulation capacity, and continue to strengthen cooperation of circulation enterprises with other industries, like manufacturing, promote the good circulation of national economy and perfect the cycling structure of supply chain. Circulation enterprises as the important link in commodity value chain and the important link of realization of value chain, have wide market demand information and date, send these data to producers' timely, which enable the upstream to produce the products on the first time that meet the market and greatly satisfy the needs of consumers and the market.

The reform can provide development direction for the technical transformation and upgrading of circulation enterprises, make up the short board of technological innovation by means of developing new industries, new technologies and new platforms, strengthen the support of technical innovation for improving supply quality, better play the leading role of scientific and technical innovation to consuming trend, stimulate effective supply by consumption, and push the technical innovation and rapid development of circulation enterprises. So the reform of the circulation enterprises can push enterprises to have technical innovation, improve the circulation capacity of enterprises and promote the circulation enterprises to cooperate with other enterprises (Dawei Zhang, 2004).

\section{Supply chain SWOT analysis of circulation enterprises}

SWOT analysis is a comprehensive analysis of the opportunities and threats in external environment of enterprises and the strengths and weaknesses of external capabilities of the enterprises. The SWOT analysis on supply chain of circulation enterprises has important significance for the reform of the circulation enterprises and making clear strengths and weaknesses, opportunities and threats. 


\subsection{Strengths}

\subsubsection{Circulation enterprises actively adapt to the change of policies}

It is reflected by that circulation enterprise groups pay attention to the strategic adjustment and transformation and upgrading, traditional logistics enterprises upgrade services and integration service trend of warehousing and distribution is evident increasingly; the third party logistics enterprises accelerate the implementation of supply chain integration services; professional logistics develops fast; mergers and acquisitions and the market concentration gradually improve; logistics enterprise information technology is upgraded widely; green logistics has become a new the norm in enterprises.

\subsubsection{SME circulation enterprises develop fast}

In terms of specialized division of labor, small and medium-sized enterprises are indispensable supporting enterprises and partners in the core enterprises of supply chain. Small and medium-sized enterprises that are small and specialized and small and fine are important members of the commercial circulation channels (Yan Zhou, 2016). From business circulation, most of the small and medium-sized enterprises participate in the supply chain management activities. In the supply chain network, the enterprises can be seen in dealers, distributors, retailers, logistics service providers. Small and medium sized enterprises are at the end of the supply chain network, and close to the customers and also know the demands and changes of customers, can timely understand the change of market departments and respond, and become an important source of information in supply chain management.

\subsubsection{Operation enviromment of logistics enterprises continue to be good}

It is reflected by government issues policies to support the development of the logistics industry; builds the integrity logistics system to continuously develop, the new third board continues to heat up and become a new way to securitize the capital of logistics enterprises, and logistics infrastructure construction has made great progress.

\subsection{Weaknesses}

\subsubsection{The supply of circulation enterprises is surplus and the cost of production factors is high}

Overcapacity in circulation enterprises is significant, which has not been solved for a long time in China. From industrial internal angle, most of circulation enterprises in China have excessive plus in productivity, the industry agglomeration is low, which causes the fierce competition among circulation enterprises. At the same time, China's circulation enterprises have serious overcapacity, waste a lot of money, labor and land and other resources, resulting in potential productivity is difficult to effectively play. The overall profit margin of China's circulation industry is low, and the attractiveness of the industry is weakened. Compared with the production-oriented enterprises, the problem of overstock inventory of circulation enterprises is obvious.

4.2.2 The supply contradiction of circulation enterprises originates from the irrational structure of retail.

(1) China's retail industry has low degree of organization, operation is not standardized, and a variety of industry advantages cannot effectively play. Many of China's retail industries use independent and single operation(Caijie Cao ,2010), namely the traditional big and complete, and 
small and complete operation, and the perfect and standardized operation monitoring system has not formed largely, which seriously restricts the development of retail chain operation, resulting in the increasing difficulty of reform to the supply of circulation enterprises.

(2) Retail industry in circulation field is small, the network structure layout is unreasonable, and the market positioning tends to assimilation. The spatial concentration of retail industry is too high. Most of the large-scale department stores in most cities are concentrated in the central business district, and the distribution is relatively concentrated.

(3) The structural adjustment of retail industry is unreasonable and is purely copied. The adjustment of modern retail industry only stays in the innovation and change at level of business form, not the result of retail market segmentation and continuous adjustment of operation and sales, the copied growth mode makes the circulation enterprises not to enlarge the grades and form the operation gradient, which causes that many enterprises quickly imitate and promote the retailing convergence development when a new merging show up on market, so that the unreasonable supply structure is formed.

\subsubsection{Poor supply of circulation enterprises is abound}

There is a large number of inferior supply of fake and inferior products in circulation enterprises in China, which is the result of the serious absence of social honesty and contract spirit, as well as the manifestation of economic market and government failure. First, due to the large number of poor supply in circulation, the consumer demands are difficult to meet. At present, the inferior supply of circulation enterprises in China seriously inhibits the effective demand, limits the development space of good supply, and produces a large-size halo effect of the inferior market, damages the system of circulation market. Second, the bad business environment exists in field of circulation enterprises, which greatly narrows the development space of circulation enterprises and restricts the brand building of production and circulation, causes the high costs paid by Chinese circulation economy and becomes outstanding increasingly in the consumption structure upgrading.

\subsubsection{The internal supply capacity of circulation enterprises has structural short board}

Most of circulation enterprises are lack of marketable products, and it is difficult to meet the market demand of upgrading the consumption structure, which is an important task for the reform. Chinese consumer groups become more rational, pay attention to "knowledge consumption" and experience, so the supply aging and recession of circulation field and promoted and the structural short board of circulation enterprises' supply capacity show up. There are many problems existing in profitable modes in supply chain supervision and internal operation for circulation enterprises, which cause the serious shortage of high quality. These mainly are reflected by that most retail enterprises take channel tolls as the main profit source, and some retail enterprises own the money of providers, which causes a serious damage to high quality supply; as far as supply chain supervision, the competition and fighting between providers, the coordination with credit is low, the mutually exclusive supply and demand relation damage the business ecological environment, which become the main reasons to restrict the good development of circulation enterprises.

\subsection{Opportunities}

\subsubsection{Supply chain logistics service demand side in the environment of Internet Plus has} undergone major changes

For example Belt and Road Initiative brought unlimited business opportunities for logistics enterprises; adjustment of economic development structure and high-end manufacturing focus on 
the optimization of supply chain; distribution business supply chain is accelerated rapidly, business logistics demands emerge, and demands of environmental protection and green logistics grows.

\subsubsection{Supply chain achieves a full range of visualization}

The information system is becoming more and more popular, the popularity of international Internet, development of ERP system and application provide the important support for the operation and development of supply chain, greatly reduces the information technology cost that circulation enterprises. In realizing informatization in circulation field, the management of supply chain is characterized by obvious effect, easy implementation and fast result. Second, the commodity bar codes as the identity cards of commodity circulation, make it possible to combine various channels effectively. Under the GSI logistics standard system, China has formed a series of code marks, such as GTIN, box code, SSCC, global position code, and so on. It realizes the omni-directional visualization of the supply chain.

\subsubsection{Supply chain 4.0 creates customer value}

(1) The focus of Chinese economy and corporate cooperation needs to pay attention to the coordination balance of various economic activities from production to supply chain, supply chain 4.0 provides methods for building the ecological system of coordination development in production, trade, logistics and finance and the operation on supply chain of circulation enterprises, and reducing the risks of trade.

(2) It takes creating customer value as the core, builds the efficient coordination in production, trade, and logistics, and realizes win-win and share benefits in the internal enterprises on supply chain, the management methods and technologies of resource integration. Through optimizing the resource allocation among upstream and downstream circulation enterprises in supply chain, the connection of links on supply chain is realized, the maximum value is achieved. While creating value for customers, the coordination of the circulation enterprises is improved as well.

\subsection{Threatens}

\subsubsection{Poor environment of medium and small circulation enterprises}

With the high price of material and energy, the rising cost of labor and the difficulty of financing, the development of small and medium circulation enterprises is facing great challenges and threats. The financial crisis triggered by the US sub-prime mortgage crisis in 2008 had has a huge impact on the global economic environment, the export of our products has shrunk year after year, and the enterprises are facing a severe competition environment and greater competition pressure, small and medium sized enterprises is small also with poor strength and low risk tolerance. and will be easily attacked, and they face a greater threat than large enterprises in the competition.

\subsubsection{The problem of information standardization leads to immaturity of logistics service supply chain network in China}

The level of enterprise informatization is not high and the level of management is low, which restricts the construction of logistics service supply chain network. In 2015, the state Council put forward the "internet plus industry" strategy, and our enterprises have begun to promote the construction of information technology. According to the data released by the China information industry center, at the end of 2015, $42.3 \%$ of enterprises have been in the stage of comprehensive application of informatization. However, in the whole, the degree of informatization of Chinese 
circulation enterprises is not high, and the management concept is backward, which seriously affects the efficiency and decision level of management and management, which leads to the construction of logistics service supply chain network in China is not comprehensive and immature.

\subsubsection{The retail industry is in a difficult position}

The foreign retail industry is no longer restricted by the equity, quantity and geographical location. since December 11, 2004, due to policy liberalization, the proportion of foreign investment increased, and easier to enter the rural market, can expand, mergers and even buy retail enterprises. In the supply side reform stage, the circulation industry survival and challenges coexist, and the large-scale expansion of foreign enterprises not only use the resources of local government, but also reduce the living space of the retail industry.

\subsubsection{Policy issues restrict the development of circulation enterprises}

Logistics is an important link in all the circulation industry, the policy of the approval of the logistics to make a great impact on the further development of the circulation industry.

However, the current decentralization and decentralization still have space, with the rapid development of China's economy, especially the popularity of internet applications, many new business models are emerging, and new requirements for the administrative examination and approval management. In the aspect of qualification examination and approval, because the logistics industry involves more administrative examination and approval and licensing management departments, the same business matter often involves multiple departments, there is a long management, repeated examination and approval.

\section{Suggestion}

\subsection{Speeding up the standardization construction of retail industry}

From the development path of the retail industry, the sustainable development of some foreign retail giants, the supply chain management model plays an important role, and the successful operation of the supply chain management mode, the construction of the standardized system is also very critical. Fundamentally speaking, in the development path of economic globalization, domestic retail industry has to connect with foreign enterprises, so in the supply chain management system, if standardized support is not existing, will inevitably lead to some contradictions and conflicts The so-called " nothing can be finished without rules", in this era of fierce competition, if there is no standardized formulation and achievement, then the outcome is only for failure.

\subsection{Setting up supply chain management thinking}

The circulation enterprises should change the improper attitude and in different wrong thought of supply chain, fully aware that supply chain management is a new mode and new choice in the tide of contemporary enterprise management, especially in the supply side reform. To change the old ideas, actively respond to the wave of supply chain management, in the supply chain dynamic alliance to seek the interests of enterprises and long-term stable development.

\subsection{International supply chain connection}

Around the national supply-side reform and " the belt and road initiative" strategy, scientific planning and construction of the international domestic logistics channel path, build the inland to 
the coastal and inland to the west cross - border international logistics thoroughfare, give full play to the advantages of rail and water transport, reduce the cost of international logistics in the midwestern region. To further improve the customs clearance environment, simplifying the customs clearance procedures, extending the clearance time, and achieve 24 - hour uninterrupted customs clearance. Cultivate world-class multinational logistics group and professional logistics enterprise group, encourage domestic enterprises to develop international capacity cooperation and integrate into the global supply chain system. Support the logistics enterprises merger and reorganization of strategic international logistics resources, improve the allocation efficiency of global logistics resources, and accelerate the formation of international logistics pattern and logistics network coordinated with the international industrial layout.

\subsection{Introduction of advanced systems and the establishment of national standards}

In the fierce market competition, the competitiveness of circulation enterprises is positively related to the system. In order to realize the modernization of logistics service and the improvement of supply chain capacity, it is necessary to introduce the international advanced system and establish the unified standard of international standards.

1) The advanced system should be introduced based on the rapid reflection of the market. Such as the international general JIT (timely service), QR (rapid response), ECR (rapid customer response), ERP (enterprise resource plan), etc.

2) Establish specialized agencies, combining the characteristics of various industries to formulate unified national standards. Through the national guidance, establish the unified standards with international standards, such as bar code standards, ID code, to promote the continuous improvement of enterprise logistics service supply chain capacity. In 2015, the state Council proposed the "China manufacturing 2025" strategy, to unify national standards can lay the first cornerstone for the manufacturing industry to enter the domestic and international market.

\subsection{Bring up full strength to circulation enterprises shortage}

1) In the profit model, the retail enterprises in the circulation field should enhance the enterprise supply chain management and internal operation ability, and change the profit model. In the enterprise procurement process, the circulation retail enterprises should expand the range and scope of the procurement of the country of origin, shorten the intermediate links, reduce the procurement costs and reduce the supply price.

2) Circulation enterprises should improve the distribution efficiency, enhance customer satisfaction, achieve rapid response, reduce costs, and establish supply chain coordination mechanism. Through the establishment of supply chain coordination mechanism, actively seek the collaborative demand forecasting and collaborative inventory regulation between manufacturers and suppliers, and rationally arrange production capacity and production rhythm for producers and retailers, and reduce inventory to meet market demand.

During the nineteenth session, the general secretary Xi Jinping noted that the main contradictions in our country had changed and translated into the contradiction between the growing needs of the people for a better life and the inadequate development of imbalances; due to the circulation enterprises link upstream, contact the characteristics of downstream customers, the balanced development of the circulation enterprises not only to promote the healthy development of the industry, remove inventory and reduce the cost but also improve consumer consumer satisfaction and consumption stickiness. 


\section{References}

[1] Caijie Cao, 2010.Analysis SWOT of retail management in China, Technologic.

[2] Chaofang Yuan, 2017. On the issue of supply chain management in retail enterprises, Chinese Hi-tech companies. 2017(7), pp.241-242

[3] Hua Zhu, 2017. Study on the problem of logistics service supply chain development in China, Logistics. 2017(5), pp.86-88

[4] Liming He,2016.Structural contradiction of supply side of China's logistics industry and its reform, Chinese Market.2016(26),pp.3-7

[5] Dawei Zhang, 2004.Supply chain management and enterprise competition, Capital University of Economics and Business.

[6] Gang Gong, 2016. On the supply side reform under the new normal, Nankai Journal.2016 (2), pp.13-20.

[7] Xinyan Wu, 2015. Thinking of retail supply chain management mode reform under hierarchy strategy, Commercial Economic Research.2015 (34), pp.18-20.

[8] Yan Zhou,2016.Analysis SWOT and Countermeasures for the development of small and medium-sized enterprises in the supply chain management environment,WEF.2016(7),PP.116-118

[9] Zhi Li, Jinfeng Yuan, 2015.Supply side reform strategy based on China's economic reality, Price theory and Practice. 2015(12), pp.12-17. 